\title{
Study on the Construction of Efficiency Evaluation System of Urban Ecological Construction Project
}

\author{
Tianmei Song \\ Xi'an Peihua College, Xi'an, China
}

\begin{abstract}
Keywords: Construction, Efficiency Evaluation System, Urban Ecological Construction Project
\end{abstract}
\begin{abstract}
With the rapid progress of industrialization and urbanization, the problem of urban ecological environment has become increasingly prominent, which has become the shackles of sustainable development. Scientific construction of urban ecological civilization evaluation index system and through the specific analysis of the object of observation data for ecological civilization evaluation is to effectively grasp the state of urban ecological civilization construction and it is conducive to the implementation of urban ecological construction performance appraisal and strengthens urban ecological risk forecasting and other work advance and development. In recent years, with the deepening of the practice of ecological civilization construction, the research on the evaluation index system of ecological civilization has been increasing day by day.
\end{abstract}

\section{Introduction}

With the rapid development of industrialization and the acceleration of the process of urbanization in the world, Chinese urbanization process has entered a stage of comprehensive development. Urbanization has played an important role in promoting the development of social, economic, transportation, production, science and technology and culture in the conceptual framework of urban economic system. On the other hand, due to the sustained growth and high concentration of urban population, the metabolic function of the city itself has a great impact on the ecological balance of nature and impact, but also on the human living environment and quality of life have a variety of adverse effects. Urban ecological construction and urban economic competitiveness as the human and natural development of the complex system of two important subsystems, they interact, mutual influence, and jointly promote the city's health, rapid and harmonious development.

In the course of urban ecological construction, the optimization of human settlements should be promoted and harmoniously with the promotion of urban economic competitiveness. However, in the traditional energy consumption mode of production, urban construction ignores the environmental carrying capacity to promote the economic and social development of the city at the expense of limited resources and the natural environment in which human beings live. In the global greenhouse effect, environmental pollution increasingly serious warning, the city should actively promote ecological construction, concerned about the problem of environmental pollution control, and constantly optimize the environmental processing capacity, and strive to achieve the city of material, energy, information a virtuous circle. Only through the urban ecological construction, improve and optimize the living environment, in order to attract more advantages of resources to serve the city's economic level, thereby enhancing the city's comprehensive competitiveness.

Economic globalization has put forward new requirements for urban competitiveness. The competitiveness of cities, especially economic competitiveness, has become a measure of the performance of cities in economic development. Therefore, to enhance the competitiveness of urban economy has become an important strategic goal of urban development. Through the improvement of urban economic competitiveness, it can provide diversified financing channels for urban ecological construction, improve the efficiency of environmental pollution control and optimize the allocation of space and time resources. Based on the interaction between urban ecological construction and urban economic competitiveness, this paper makes an in-depth analysis of the synergistic relationship between them, and tries to explore the synergistic mechanism of common development. The research of this paper can provide the development path and train of thought for the improvement of urban 
ecological construction and urban economic competitiveness, which is of great practical significance to the development of urban economy and society. In addition, the paper focuses on the study of urban ecological construction and urban economic competitiveness between the internal mechanism of action and harmonious symbiotic relationship, through the coordination of the two studies can provide for the city managers can learn from and operational strategies and methods, Therefore, the research of this paper has significant practical significance. At the same time, the research of this thesis analyzes the urban ecological construction and the urban economic competitiveness from the perspective enriches the theoretical system of social synergy, and expands the theoretical system framework of urban ecological construction and urban competitiveness research has a certain theoretical research value.

\section{The Characteristics of Urban Ecological Construction}

It is the overall goal of urban ecological construction. To realize this goal, we should give full play to the innovation and initiative of the people as the theme of the activity, and constantly improve the ecological environment that the city can bear as the complex ecosystem. Bearing capacity, and enhance the ability of self-repair and regeneration within the ecosystem, and finally realize the harmony degree of ecological-economic-social complex urban ecosystem and the level of ecological civilization. From the natural - economic - social complex urban ecosystem construction content analysis, urban ecological construction should have the following basic characteristics:

The balance of sub-system. Migration ecosystem theory, urban ecosystem is a complex system composed of interdependent natural, economic and social subsystems. The process of urban ecological construction should strengthen its prosperity and optimize the environment at the same time, but also take into account the common benefits of nature, economy and society. Therefore, the various subsystems in the urban complex system should be balanced and coordinated.

The harmony of development. Urban ecosystems cover a variety of constituent elements, and only follow the interaction between the elements of the relationship in order to achieve the development of harmony. The relationship between these elements includes: between people, people and nature, economic and social development and nature protection, artificial environment and the natural environment, etc., and try to determine the virtuous circle and order.

The sustainability of urban construction. According to the basic theory of sustainable development, urban ecological construction should take into account the geographical location and space-time characteristics, urban construction should not only consider the contemporary development, but also should focus on the development of future generations, therefore, the city's construction should fully reflect the sustainable and to ensure the sustainability, health and coordination of urban development.

The regional construction. According to the differences of urban geographical location, regional differences should be taken into account in urban ecological construction, especially in the process of national ecological construction, and the ecological construction of cities in different regions should be balanced as much as possible.

The ecological construction efficiency. Because of the early development of modern cities, it depends on the operation mode of "non-circulation" and "high energy consumption", but with the improvement of human cognition to the ecological environment, the external environment factors should be taken into account in the urban construction to realize the efficient use of resources and reduce the environment pollution levels, and coordination of various sectors and departments of the coordination and symbiosis, and strive to promote a virtuous circle of urban environment.

\section{The Problems in Chinese Existing Urban Ecological Construction Project Efficiency Effect Evaluation System}

Lack of spatial structure optimization indicators. For the existing ecological civilization evaluation index system on the lack of spatial structure optimization indicators, the government 
through the location environment and policy environment such as the relevant policy making, infrastructure construction, open market construction and other investment soft and hard environment reform and improvement of urban agglomeration development the impact of the adoption of industrial policies or other relevant policies to guide the location of enterprises to jointly develop the appropriate coordination mechanism to coordinate the layout of the industry between cities, the development and layout of the city, urban transport and other communications network communication network construction activities, which led to the evolution of the spatial structure of urban agglomerations. This paper puts forward the degree of optimization of spatial structure of urban ecological civilization from the aspects of land development intensity, unit GDP energy consumption and per capita housing area.

The economic and social development indicators weight is too large. The city is mainly based on economic and social development indicators to build ecological civilization construction evaluation index system, and economic and social indicators of weight are too large, affecting the final evaluation results. The direct impact of which city is the economic development and construction of prominent, which city per capita income level is high, which city's ecological civilization construction level is higher, and people's understanding of ecological civilization construction has deviated, such as Beijing's economic construction the level of economic and social development than other cities in the country to be much higher, but people are the impression that Beijing is often dust storms, lack of groundwater and other ecological and environmental disasters, seriously affecting the normal life of urban residents order, so the construction of ecological civilization Evaluation of the index system design, should be more scientific set of economic and social development indicators of the weight, more scientific reflection of the evaluation of the region's ecological civilization construction level.

Lack of ecological civilization system construction indicators. The indicators of ecological civilization system in Xiamen eco-civilization construction index are: environmental indicators included in the performance evaluation of party and government leading cadres, ecological environment motion, proposal, recommended proportion (\%), planning environmental impact assessment implementation rate (\%). Guiyang City, the construction of ecological civilization evaluation index system does not mention the construction of ecological civilization system indicators. The indicators of economic and social development in the evaluation index system of ecological and civilized construction of Changsha, Zhuzhou and Xiangtan are: the degree of ecological environment laws and regulations, the degree of implementation of laws and regulations of ecological environment. These two indicators reflect the ecological civilization system of ecological and environmental protection, the construction of ecological civilization in the construction of the coverage is not enough. Therefore, from the city's system construction indicators, there are indicators of the lack of indicators and reflect the problem of one-sided problem. In addition, there are some indicators in the practical application of data collection difficulties or cannot collect the calculation of the problem and the ecological civilization construction evaluation index system has an impact on the operability.

\section{The Index Selection of Efficiency Evaluation System for City Ecological Construction Projects}

From the connotation of the construction of ecological civilization system, we can find that the system of ecological civilization is strengthened so that resource consumption, environmental loss and ecological benefit are included in the evaluation system, and economic and social development is carried out to reflect the ecological requirements of civilized index system, assessment method and incentive mechanism. Protection system to establish land development space, improve the most stringent arable land protection system, water resources management system, environmental protection system. Deepen the price of resource products and tax reform reflect the market supply and demand and the scarcity of resources, reflecting the ecological value and resources and ecological compensation system, paid use of intergenerational compensation system. Strengthen environmental supervision improve the protection of the ecological environment and accountability system for 
environmental damage compensation system. Strengthen the ecological civilization education, enhance the social ecology, environmental awareness, ecological awareness and rational social consumption habits in the form of people's awareness, and create a good atmosphere to cherish the environment.

The construction of ecological civilization system is to solve the social problems, to solve social problems must be unified in the whole society norms, from the perspective of the whole society for macroeconomic resources, environment, ecology and other issues to legislation and the establishment of rules and regulations, Through the introduction of mandatory laws and regulations and rules and regulations to regulate the behavior of society as a whole. According to the proportion of resource saving and eco - environmental protection investment, the government 's clean index, the efficiency of administrative service, the construction of ecological civilization accounted for the proportion of party and government performance, and the five indexes of citizen satisfaction were evaluated respectively.

The proportion of resource conservation and eco-environmental protection investment: the proportion of resource conservation and eco-environmental protection investment refers to the proportion of investment in environmental pollution control investment in the province within the current administrative division of the province. Resource conservation and ecological environmental protection investment is the city in the implementation of policy planning, the construction of ecological civilization, the intensity of investment.

The government cleanliness index: Reflective index reflects the integrity and bribery of a state government official, with entrepreneurs, risk analysts, the general public as the object of the survey, according to their experience and feelings for countries from 10 to 0 score, The higher the score, the lower the degree of corruption. Calculation method: government clean index $=$ number of corruption cases / population.

Administration efficiency: administrative efficiency refers to the public organizations and administrative staff engaged in public administration work by the various resources and the results achieved and the proportion of the relationship between the benefits.

Ecological civilization construction accounted for the proportion of party and government performance: the public in the eyes of government performance, not just with simple GDP and other economic development of hard targets. How to realize the effective communication between the government and the public, how to better realize the government function is the new problem faced by the local people at present.

Citizen's satisfaction: including the improvement of the material life of the masses, the act of law, the openness of the government, the level of service and the construction of the organs, the mass sports activities, the civil moral education, the creation of civilized cities and towns, the units, the expansion of employment and social security, Income and housing, improve traffic and production and living environment, to solve their children's enrollment and health care, social security comprehensive management, mass petition incident handling, the party's grassroots organizations and party members, cadres, personnel, party building.

\section{Conclusion}

Ecological civilization is a new civilization after the original civilization, agricultural civilization and industrial civilization. The ecological civilization construction is a long process to solve the current face of the grim resource and environmental problems especially for different areas of resources and environmental issues developed the implementation of differentiated ecological civilization construction policy is a realistic choice for the smooth realization of our country's ecological civilization construction. Chinese resources and environmental problems regional differences, the different areas of resources and environmental problems faced by the focus is not the same, only the objective and reasonable understanding and grasp the respective regions in the resources and environmental issues in the advantages and disadvantages, increase the advantages, 
make up for deficiencies, so that the construction of ecological civilization in China will successfully complete.

\section{References}

[1] B. N. Ma, Good Habitat and Planning Change, J. Urban Planning. 44 (2010) 146-147.

[2] H.X.Zeng, Ecological reward and punishment mechanism and the construction of ecological civilization in China. J. Environmental Protection and Circular Economy. 18(2005) 55-57.

[3] J.H.Xue, Research on the Logic and Significance of the Evolution of the Overall Layout of the Socialism with Chinese Characteristics, J. Marxist Studies, 32(2012) 189-190.

[4] Y.J.Qi, Research on the New Vision of Ecological Civilization, J. Journal of Beijing University of Technology, 4(2007) 38-40.

[5] Y.M.Tian, Research on the natural factors and institutional factors that lead to the widening income gap between urban and rural residents in the process of industrialization, J. Economic Commentary (2013) 142-150. 